This article was downloaded by: [National Taiwan University]

On: 10 November 2008

Access details: Access Details: [subscription number 788856085]

Publisher Taylor \& Francis

Informa Ltd Registered in England and Wales Registered Number: 1072954 Registered office: Mortimer House, 37-41 Mortimer Street, London W1T 3JH, UK

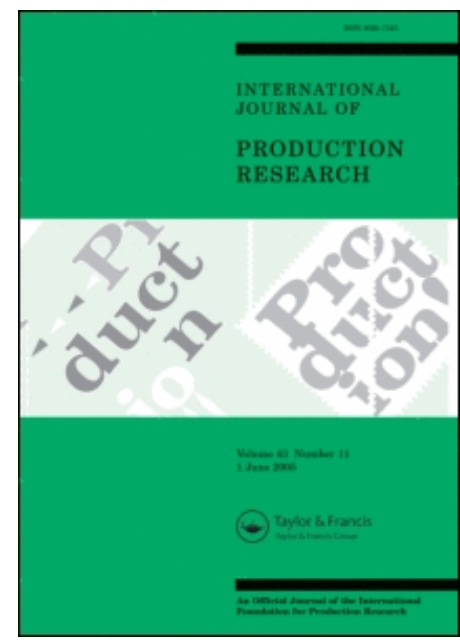

International Journal of Production Research

Publication details, including instructions for authors and subscription information:

http://www.informaworld.com/smpp/title content=t713696255

\title{
Optimization of machining parameters of Wire-EDM based on Grey relational
} and statistical analyses

J. T. Huang a; Y. S. Liao ${ }^{\mathrm{b}}$

a Department of Automatic Engineering, Kaoyuan Institute of Technology, Luchu, Kaohsiung, 821, Taiwan. ${ }^{\text {b }}$

Department of Mechanical Engineering, National Taiwan University, Taipei, 106, Taiwan.

Online Publication Date: 20 January 2003

To cite this Article Huang, J. T. and Liao, Y. S.(2003)'Optimization of machining parameters of Wire-EDM based on Grey relational and statistical analyses',International Journal of Production Research,41:8,1707 - 1720

To link to this Article: DOI: $10.1080 / 1352816031000074973$

URL: http://dx.doi.org/10.1080/1352816031000074973

\section{PLEASE SCROLL DOWN FOR ARTICLE}

Full terms and conditions of use: http://www.informaworld.com/terms-and-conditions-of-access.pdf

This article may be used for research, teaching and private study purposes. Any substantial or systematic reproduction, re-distribution, re-selling, loan or sub-licensing, systematic supply or distribution in any form to anyone is expressly forbidden.

The publisher does not give any warranty express or implied or make any representation that the contents will be complete or accurate or up to date. The accuracy of any instructions, formulae and drug doses should be independently verified with primary sources. The publisher shall not be liable for any loss, actions, claims, proceedings, demand or costs or damages whatsoever or howsoever caused arising directly or indirectly in connection with or arising out of the use of this material. 


\title{
Optimization of machining parameters of Wire-EDM based on Grey relational and statistical analyses
}

\author{
J. T. HUANG $\dagger^{*}$ and Y. S. LIAO $\ddagger$
}

\begin{abstract}
Grey relational analyses are applied to determine the optimal selection of machining parameters for the Wire Electrical Discharge Machining (Wire-EDM) process. The Grey theory can provide a solution for a system in which the model is unsure or the information is incomplete. Besides, it provides an efficient solution to the uncertainty, multi-input and discrete data problem. Based on Taguchi quality design concept, an L18 mixed-orthogonal array table was chosen for the experiments. With both Grey relational analysis and a statistical method, it is found that the table feedrate had a significant influence on the metal removal rate, whilst the gap width and surface roughness were mainly influenced by pulseon time. Moreover, the optimal machining parameters' setting for maximum metal removal rate and minimum surface roughness (or a desired surface roughness or a desired gap width) could be obtained by this approach.
\end{abstract}

\section{Introduction}

Wire electrical discharge machining (Wire-EDM) involves a series of heating and cooling process. Electrical discharge happens when a workpiece and wire-electrode are very close (about 5-50 $\mu \mathrm{m}$ ) with a gap voltage supplied. The Wire-EDM process is shown in figure 1. A machine must have good static and dynamic characteristics to obtain optimal performance. In addition, machining parameters, including pulse-on time, pulse-off time, table feedrate, flushing pressure, wire tension, wire velocity, etc., should be chosen properly. However, the selection of appropriate machining parameters for Wire-EDM is difficult and relies heavily on operators' experience.

Grey theory can provide a solution to a system in which the model is unsure or the information is incomplete (Deng 1990). It also provides an efficient solution to the uncertainty, multi-input and discrete data problem. The relation between machining parameters and performances can be found by using the Grey relational analysis. Also, the Grey relational grade $(\Gamma)$ can use the discrete measurement method to measure the distance.

Computer-aided process planning (CAPP) has been proposed since 1960 (Ham and Lu 1988). Determination of machining parameters was part of the CAPP system. Some researches related to machining parameters' setting were studied in order to determine those parameters effectively and optimally, and, moreover, they

Revision received October 2002.

$\dagger$ Department of Automatic Engineering, Kaoyuan Institute of Technology, Luchu, Kaohsiung, 821, Taiwan.

$\$$ Department of Mechanical Engineering, National Taiwan University, Taipei, 106, Taiwan.

* To whom correspondence should be addressed. e-mail: tsung@cc.kyit.edu.tw or expert56@ms33.hinet.net 


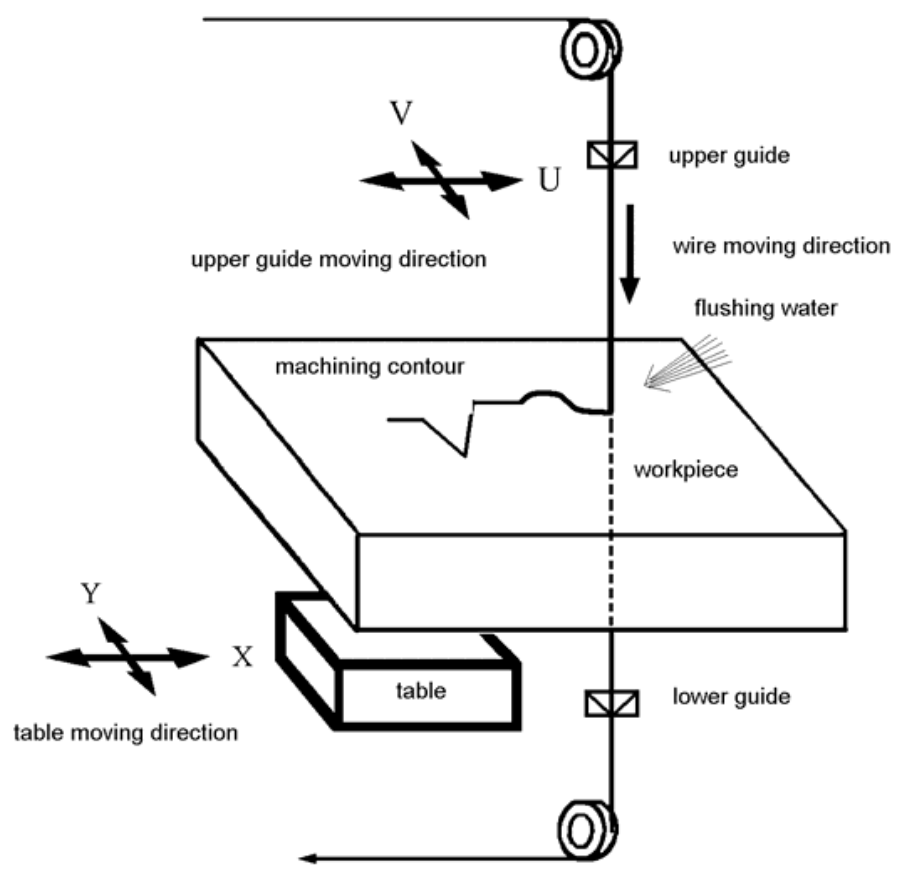

Figure 1. Wire-EDM process.

can be embedded in the CAPP system. Kishi et al. (1989) proposed the method of nonlinear programming to find the optimal machining parameters. Staelens and Kruth (1989) proposed an appropriate strategy assisted by computer to decide the optimal machining process.

An estimating calculation method was proposed for a multicut Wire-EDM process (Kravets 1992). The machining volume and metal removal rate were both functions of surface roughness, but they were difficult to estimate accurately. Further, the approach to determine the optimal machining parameters for each operation such pulse-on time, pulse-off time, etc. was not discussed. Scott et al. (1991) used a factorial design method to determine the optimal combination of control parameters in Wire-EDM. A number of 32 machining settings, which resulted in a better metal removal rate and surface roughness, were determined from 729 experiments. This approach required too many experiments, however. Tarng (1995) applied neural network with a simulated annealing (SA) algorithm to determine the optimal machining parameters in the Wire-EDM process. However, it could not provide the optimal machining parameters for a desired surface roughness. Liao (1997) presented an approach to determine the optimal parameters' setting based on the Taguchi Quality experiment design, analysis of variance, regression analysis and feasible direction. Lin (1998) presented the use of Grey theory to the optimization of the EDM multiresponse process. However, it could not provide the optimal machining parameters for a desired surface roughness.

Therefore, there is still some difficulty in determining the optimal machining parameters: the cost of and time-consuming nature of conducting experiments, the many machining parameters and the real mathematical models are hard to derive. The purpose of this paper is to present an efficient method to find the significant 
parameters affecting machining performance for Wire-EDM based on Grey relational analysis and a statistical method. In addition, the combination of optimal machining parameters for maximum machining speed and minimum surface roughness can be obtained by applying Grey relational analysis. Furthermore, it is feasible for the Grey relational analysis to obtain the optimal machining parameters' setting for a desired surface roughness and maximum metal removal rate (or a desired gap width).

\section{Experimental design}

Experiments were carried out on a Wire-EDM machine with an iso-energy pulse generator. The workpiece material (anode) was SKD11 alloy steel of $30 \mathrm{~mm}$ height. The electrode (cathode) was $0.25 \mathrm{~mm}$ diameter brass wire. The fluid specific resistance was between $10^{4}$ and $10^{6} \Omega \mathrm{cm}$. The open voltage and servo reference voltage was set as 95 and $10 \mathrm{~V}$, respectively.

According to the Taguchi quality design concept (Ross 1986), an L18 mixedorthogonal array table was chosen for the experiments (table 1). Six machining parameters (table feedrate, pulse-on time, pulse-off time, wire tension, wire velocity, fluid pressure) were chosen for the controlling factors, and each parameter was designed to have three levels, denoted by 1, 2 and 3, as shown in table 2 (only two levels for table feedrate). The machining results after Wire-EDM process were evaluated in terms of the following measured machining performance: (1) metal removal rate (MRR, $\left.\mathrm{mm}^{3} \mathrm{~min}^{-1}\right)$; (2) gap width $(G, \mathrm{~mm})$; and (3) surface roughness $\left(R_{\mathrm{a}}, \mu \mathrm{m}\right)$. The same experiment was conducted repeatedly three times.

\begin{tabular}{rrrrrrrrrr}
\hline & \multicolumn{7}{c}{ Factors } \\
\cline { 2 - 9 } No. & $F_{\mathrm{r}}$ & $T_{\text {on }}$ & $T_{\text {off }}$ & $V_{\mathrm{w}}$ & $F_{\mathrm{w}}$ & $P$ & $E_{1}$ & $E_{2}$ \\
\hline 1 & 1 & 1 & 1 & 1 & 1 & 1 & 1 & 1 \\
2 & 1 & 1 & 2 & 2 & 2 & 2 & 2 & 2 \\
3 & 1 & 1 & 3 & 3 & 3 & 3 & 3 & 3 \\
4 & 1 & 2 & 1 & 1 & 2 & 2 & 3 & 3 \\
5 & 1 & 2 & 2 & 2 & 3 & 3 & 1 & 1 \\
6 & 1 & 2 & 3 & 3 & 1 & 1 & 2 & 2 \\
7 & 1 & 3 & 1 & 2 & 1 & 3 & 2 & 3 \\
8 & 1 & 3 & 2 & 3 & 2 & 1 & 3 & 1 \\
9 & 1 & 3 & 3 & 1 & 3 & 2 & 1 & 2 \\
10 & 2 & 1 & 1 & 3 & 3 & 2 & 2 & 1 \\
11 & 2 & 1 & 2 & 1 & 1 & 3 & 3 & 2 \\
12 & 2 & 1 & 3 & 2 & 2 & 1 & 1 & 3 \\
13 & 2 & 2 & 1 & 2 & 3 & 1 & 3 & 2 \\
14 & 2 & 2 & 2 & 3 & 1 & 2 & 1 & 3 \\
15 & 2 & 2 & 3 & 1 & 2 & 3 & 2 & 1 \\
16 & 2 & 3 & 1 & 3 & 2 & 3 & 1 & 2 \\
17 & 2 & 3 & 2 & 1 & 3 & 1 & 2 & 3 \\
18 & 2 & 3 & 3 & 2 & 1 & 2 & 3 & 1 \\
\hline
\end{tabular}

Table 1. L18 mixed-orthogonal-array table. $F_{\mathrm{r}}$, feedrate; $T_{\text {on }}$, pulse-on time; $T_{\text {off }}$, pulse-off time; $V_{\mathrm{w}}$, wire velocity; $F_{\mathrm{w}}$, wire tension; $P$, fluid pressure; $E_{1}$ and $E_{2}$, error factors. 


\begin{tabular}{|c|c|c|c|c|c|}
\hline \multirow{2}{*}{\multicolumn{2}{|c|}{ Machining parameters }} & \multicolumn{3}{|c|}{ Levels } & \multirow[b]{2}{*}{ Unit } \\
\hline & & 1 & 2 & 3 & \\
\hline 1 & Table feedrate & 0.4 & 2.5 & - & $\mathrm{mm} \min ^{-1}$ \\
\hline 2 & Pulse-on time & 0.3 & 0.7 & 1 & $\mu \mathrm{s}$ \\
\hline 3 & Pulse-off time & 9.6 & 14.4 & 20.8 & $\mu \mathrm{s}$ \\
\hline 4 & Wire velocity & 6 & 9 & 12 & $\mathrm{~m} \min ^{-1}$ \\
\hline 5 & Wire tension & 8 & 10 & 12 & $\mathrm{~N}$ \\
\hline 6 & Fluid pressure & 3 & 5 & 7 & $\left(\times 10^{5}\right) \mathrm{Pa}$ \\
\hline
\end{tabular}

Table 2. Levels of experimental machining parameters.

\subsection{Notation}

$\Gamma$ grey relational grade,

MRR metal removal rate,

$G$ gap width,

$R_{\mathrm{a}}$ surface roughness,

$F_{\mathrm{r}}$ table feedrate,

$T_{\text {on }}$ pulse-on time,

$T_{\text {off }}$ pulse-off time,

$V_{\mathrm{w}}$ wire velocity,

$F_{\mathrm{w}}$ wire tension,

$P$ fluid (flushing) pressure,

$(X, \Gamma)$ Grey relational space,

$x_{0}(k)$ reference sequence,

$x_{i}(k)$ comparative sequences,

HB higher is better,

LB lower is better,

$\eta$ signal-to-noise $(\mathrm{S} / \mathrm{N})$ ratio,

$S_{\mathrm{T}}$ sum of squares due to total variation,

$S_{\mathrm{m}}$ sum of squares due to the mean,

$S_{\mathrm{A}}$ sum of squares due to factor $\mathrm{A}\left(\mathrm{A}=F_{\mathrm{r}}, T_{\text {on }}, T_{\text {off }}, V_{\mathrm{w}}, F_{\mathrm{w}}, P\right)$,

$S_{\mathrm{E}}$ sum of squares due to errors,

$\eta_{i} \quad \eta$ value of each experiment $(i=1-18)$,

$\eta_{\mathrm{A} i}$ sum of $i$ level of factor $\mathrm{A}(i=1,2$ or $1,2,3)$,

$N$ repeating number of each level of factor $\mathrm{A}$,

$f_{\mathrm{A}}$ degree of freedom of factor $\mathrm{A}$,

$V_{\mathrm{A}}$ variance of factor $\mathrm{A}$,

$F_{\mathrm{AO}}$ ratio of variance of factor $A$ to the variance of errors,

$F_{0.05, n 1, n 2}$ reference value $>95 \%$ distribution for degree $n_{1}$ and $n_{2}$.

\section{Grey relational analysis}

Grey theory established by Deng (1989) includes Grey relational analysis, Grey modelling, prediction and decision-making of a system in which the model is unsure or the information incomplete. It provides an efficient solution to the uncertainty, multi-input and discrete data problem. The relation between machining parameters and machining performance can be found out by using the Grey relational analysis. This kind of interaction is mainly through the connection among machining para- 
meters and the same conditions that are already known. In addition, it will indicate the relational degree between two sequences with the help of Grey relational analysis. Moreover, the Grey relational grade $(\Gamma)$ can use the discrete measurement method to measure the distance.

When the range of the sequence is too large or the standard value is too enormous, it will cause the influence of some factors to be neglected. In addition, in the sequence, if the factors' goals and directions are different, the relational analysis might also produce incorrect results. Therefore, preprocessing of all the data is necessary. This process is the so-called as Grey relational generating. There are three different types.

(1) Higher is better (HB):

$$
x_{i}^{*}(k)=\frac{x_{i}^{(0)}(k)-\min x_{i}^{(0)}(k)}{\max x_{i}^{(0)}(k)-\min x_{i}^{(0)}(k)} ;
$$

(2) Lower is better (LB):

$$
x_{i}^{*}(k)=\frac{\max x_{i}^{(0)}(k)-x_{i}^{(0)}(k)}{\max x_{i}^{(0)}(k)-\min x_{i}^{(0)}(k)} ;
$$

(3) Desired value $x^{(0)}$ :

$$
x_{i}^{*}(k)=1-\frac{\left|x_{i}^{(0)}(k)-x^{(0)}\right|}{\max x_{i}^{(0)}(k)-x^{(0)}} ;
$$

where $x_{i}^{*}(k)$ is the generating value of Grey relational analysis, $\min x_{i}^{(0)}(k)$ is the minimum value of $x_{i}^{(0)}(k), \max x_{i}^{(0)}(k)$ is the maximum value of $x_{i}^{(0)}(k)$ and $x^{(0)}$ is the desired value.

The term 'Grey relational grade, $\Gamma$ ' is used to show the relationship among those series. Let $(X, \Gamma)$ be a Grey relational space, where $X$ is the collection of Grey relational factors, and let $x_{i}(k)$ be the comparative series, $x_{0}(k)$ the reference series:

$$
\begin{aligned}
& x_{0}(k)=x_{0}(1), x_{0}(2), \ldots, x_{0}(n) \\
& x_{i}(k)=x_{i}(1), x_{i}(2), \ldots, x_{i}(n) \in X,
\end{aligned}
$$

where $i=1, \ldots, m$.

Then, the Grey relational grade can be calculated by equation (6) (Hsia and $\mathrm{Wu}$ 1998). $\Delta_{\min }$ and $\Delta_{\max }$ is the minimum and maximum value among all the $\Delta_{o i}$ values, respectively. $\Delta_{o i}(k)$ is the absolute value of difference between $x_{0}$ and $x_{i}$ at the $k$ th point.

$$
\Gamma_{o i}=\frac{\Delta_{\min }+\Delta_{\max }}{\Delta^{\prime}+\Delta_{\max }} .
$$

where (1) $i=1, \ldots, m, k=1, \ldots, n, j \in i$

(2) $x_{0}(k)$ : reference sequence, $x_{i}(k)$ : comparative sequences

(3) $\Delta_{o i}(k)=\left|x_{0}(k)-x_{i}(k)\right|$

(4) $\Delta_{\min }=\min _{\forall j \in i} \min _{\forall k}\left|x_{0}(k)-x_{j}(k)\right|$

(5) $\Delta_{\max }=\max _{\forall j \in i} \max _{\forall k}\left|x_{0}(k)-x_{j}(k)\right|$ 


$$
(6) \Delta^{\prime}=\sqrt{\sum_{k=1}^{n}\left(\frac{\Delta_{o i}^{2}(k)}{n}\right)} \text {. }
$$

\section{Statistical analysis}

\subsection{Calculation of the $S / N$ ratio}

The characteristic that the higher value represents better machining performance, such as MRR, is called HB (higher is better). Inversely, LB stands for 'lower is better', such as $R_{\mathrm{a}}$. The $S / N$ ratio (signal-to-noise ratio, $\eta$ ) is an effective representation to find significant parameters by evaluating minimum variance. A higher $S / N$ means the better performance for both $\mathrm{HB}$ and LB. The definition of $S / N$ ratio for machining performance $y_{i}$ of three repeated numbers $(i=1,2,3)$ is computed thus:

$$
\begin{aligned}
& \text { HB: } \eta=10 \times \log \left\{1 /\left[\frac{1}{n}\left(\frac{1}{y_{1}^{2}}+\frac{1}{y_{2}^{2}}+\cdots+\frac{1}{y_{n}^{2}}\right)\right]\right\} \\
& \text { LB: } \eta=10 \times \log \left\{1 /\left[\frac{1}{n}\left(y_{1}^{2}+y_{2}^{2}+\cdots+y_{n}^{2}\right)\right]\right\} .
\end{aligned}
$$

\subsection{Analysis of variance and F-test}

To assure significant machining parameters, analysis of variance (ANOVA) and an $F$-test are used to analyse the experimental data with the above-calculated $\eta$ values as follows:

$$
\begin{array}{ll}
S_{m}=\frac{\left(\sum \eta_{i}\right)^{2}}{18}, & S_{T}=\sum \eta_{i}^{2}-S_{m} \\
S_{A}=\frac{\sum \eta_{A i}^{2}}{N}-S_{m}, & S_{E}=S_{T}-\sum S_{A},
\end{array}
$$

where $S_{\mathrm{T}}$ is the sum of squares due to the total variation, $S_{\mathrm{m}}$ is the sum of squares due to the mean, $S_{\mathrm{A}}$ is the sum of squares due to factor A (A $=F_{\mathrm{r}}, T_{\mathrm{on}}, T_{\mathrm{off}}, V_{\mathrm{w}}, F_{\mathrm{w}}$, $P), S_{\mathrm{E}}$ is the sum of squares due to error, $\eta_{i}$ is the $\eta$ value for each experiment ( $i=1-$ $18), \eta_{\mathrm{A} i}$ is the sum of $i$ level of factor $\mathrm{A}(i=1,2$ or $1,2,3)$ and $N$ is the repeating number of each level of factor A.

An $F$-test was used to determine if the variance of the significant factor was bigger than the variance of error. An $F$-test value is defined as follows:

$$
V_{A}=\frac{S_{A}}{f_{A}}, \quad F_{A 0}=\frac{V_{A}}{V_{E}},
$$

where $f_{A}$ is the degree of freedom of factor $\mathrm{A}, V_{A}$ is the variance of factor $\mathrm{A}$ and $F_{\mathrm{AO}}$ is the ratio of variance of factor A to the variance of errors. The significant factors can be found for the reason that $F_{\mathrm{AO}}>F_{0.05, n 1, n 2} . F_{0.05, n 1, n 2}$ is the reference value where there is a $>95 \%$ distribution for degree $n_{1}$ and $n_{2}$.

\section{Results and analysis}

\subsection{Significant machining parameters}

\subsubsection{Statistical analysis}

Figure 2 shows the procedure for finding significant machining parameters by statistical analysis. To calculate the $S / N$ ratio $(\eta)$ of each machining performance in 


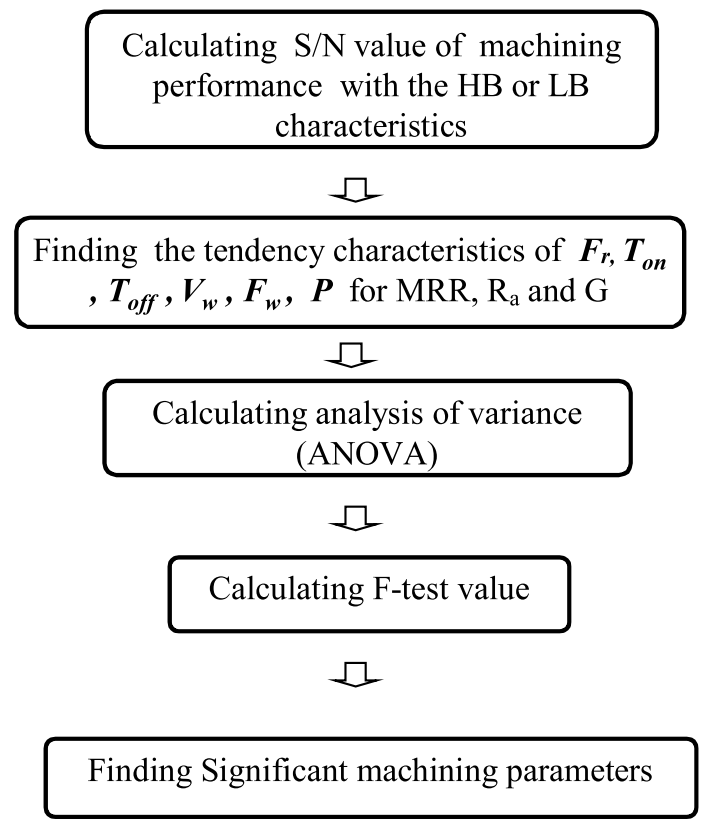

Figure 2. Flow chart for finding significant machining parameters by statistical analysis.

each experiment, the MRR (HB) was substituted into equation (7) and $R_{\mathrm{a}}$ and $G$ (LB) were substituted into equation (8) based on the measured data in table 3 for three repeated experiments. The calculated $\eta$ 's for the 18 experiments are shown in table 4. To obtain the effects of each machining parameter on each machining performance for each level, the $\eta$ 's with same level of machining parameter are summed for the 18 experiments. Taking $T_{\text {on }}$ on MRR as an example, the $\eta$ 's of three levels can be summarized as follows (tables 1 and 4):

$$
\begin{aligned}
& \text { Level 1: } \eta_{\text {on } 1}=11.86+11.72+11.29+13.32+14.82+13.99=77.0 . \\
& \text { Level 2: } \eta_{\text {on2 }}=14.12+13.39+14.23+29.98+29.92+30.20=131.83 . \\
& \text { Level 3: } \eta_{\text {on3 }}=14.81+14.52+16.52+30.70+29.17+29.68=135.40 .
\end{aligned}
$$

Similarly, those $\eta$ 's for other parameters on other machining performance could be evaluated. The total $\eta$ 's for three levels of six parameters on MRR, $R_{\mathrm{a}}$ and $G$ can be obtained as shown in table 5. An asterisk (*) means that the level value results in a better machining performance. For MRR, it was found that a larger $T_{\text {on }}, F_{\mathrm{r}}$ and $T_{\text {off }}$ are better, while smaller $V_{\mathrm{w}}, F_{\mathrm{w}}$ and medium $P$ are better.

Analysis of variance (ANOVA) and an $F$-test are used to find out the significant machining parameters. Taking MRR as an example, the square sum, variance and $F$ test value of machining parameters on MRR (tables 6 and 7) were obtained by substituting those $\eta$ 's from table 5 into equations (9) and (10). It was found that $F_{\mathrm{r}}$ and $T_{\mathrm{on}}$ are the significant factors for MRR for the reason that both $F_{\mathrm{AO}}$ values are bigger than $F_{0.05, n 1, n 2}$. Similarly, the significant parameters for each machining performance can be obtained as shown in table 7. It is obvious that $R_{\mathrm{a}}$ and $G$ were influenced mainly by $T_{\text {on }}$. 


\begin{tabular}{|c|c|c|c|c|c|c|c|c|c|c|c|c|}
\hline \multirow[b]{2}{*}{ No. } & \multicolumn{4}{|c|}{$\operatorname{MRR}\left(\mathrm{mm}^{3} \mathrm{~min}^{-1}\right)$} & \multicolumn{4}{|c|}{$R_{\mathrm{a}}(\mu \mathrm{m})$} & \multicolumn{4}{|c|}{$G(\mathrm{~mm})$} \\
\hline & 1 & 2 & 3 & Average & 1 & 2 & 3 & Average & 1 & 2 & 3 & Average \\
\hline 1 & 3.95 & 3.96 & 3.85 & 3.92 & 1.92 & 1.89 & 1.83 & 1.88 & 0.34 & 0.34 & 0.33 & 0.34 \\
\hline 2 & 3.83 & 3.9 & 3.84 & 3.86 & 1.96 & 1.95 & 1.82 & 1.91 & 0.32 & 0.32 & 0.3 & 0.31 \\
\hline 3 & 3.61 & 3.71 & 3.69 & 3.67 & 1.87 & 1.89 & 1.85 & 1.87 & 0.31 & 0.32 & 0.34 & 0.32 \\
\hline 4 & 5.03 & 5.1 & 5.12 & 5.08 & 2.48 & 2.48 & 2.5 & 2.487 & 0.43 & 0.43 & 0.41 & 0.42 \\
\hline 5 & 4.66 & 4.64 & 4.71 & 4.67 & 2.48 & 2.51 & 2.46 & 2.483 & 0.39 & 0.39 & 0.39 & 0.39 \\
\hline 6 & 5.05 & 5.24 & 5.16 & 5.15 & 2.36 & 2.37 & 2.37 & 2.367 & 0.43 & 0.43 & 0.44 & 0.43 \\
\hline 7 & 5.34 & 5.49 & 5.7 & 5.51 & 3.1 & 3.09 & 3.1 & 3.097 & 0.45 & 0.46 & 0.48 & 0.46 \\
\hline 8 & 5.28 & 5.4 & 5.28 & 5.32 & 3.12 & 3.14 & 3.16 & 3.14 & 0.45 & 0.45 & 0.45 & 0.45 \\
\hline 9 & 7.28 & 6.55 & 6.36 & 6.73 & 2.99 & 2.99 & 2.93 & 2.97 & 0.43 & 0.43 & 0.44 & 0.43 \\
\hline 10 & 4.61 & 4.55 & 4.75 & 4.64 & 1.74 & 1.75 & 1.74 & 1.743 & 0.3 & 0.31 & 0.31 & 0.31 \\
\hline 11 & 5.72 & 5.47 & 5.35 & 5.51 & 2.06 & 2.08 & 2.12 & 2.087 & 0.31 & 0.31 & 0.31 & 0.31 \\
\hline 12 & 5.17 & 4.91 & 4.96 & 5.01 & 1.78 & 1.8 & 1.82 & 1.8 & 0.31 & 0.31 & 0.31 & 0.31 \\
\hline 13 & 31.77 & 31.84 & 31.02 & 31.54 & 2.61 & 2.6 & 2.62 & 2.61 & 0.4 & 0.4 & 0.38 & 0.39 \\
\hline 14 & 31.03 & 31.99 & 30.97 & 31.33 & 2.59 & 2.63 & 2.61 & 2.61 & 0.42 & 0.42 & 0.42 & 0.42 \\
\hline 15 & 32.39 & 32.24 & 32.35 & 32.33 & 2.61 & 2.62 & 2.58 & 2.603 & 0.4 & 0.4 & 0.4 & 0.4 \\
\hline 16 & 34.36 & 34.59 & 33.92 & 34.29 & 3.06 & 3.06 & 3.05 & 3.057 & 0.44 & 0.44 & 0.44 & 0.44 \\
\hline 17 & 28.98 & 28.94 & 28.32 & 28.75 & 3.07 & 3.03 & 3.13 & 3.077 & 0.4 & 0.4 & 0.39 & 0.4 \\
\hline 18 & 30.01 & 30.66 & 30.74 & 30.47 & 3.11 & 3.17 & 3.1 & 3.127 & 0.41 & 0.42 & 0.42 & 0.42 \\
\hline
\end{tabular}

Table 3. Measured data of machining performance.

\subsubsection{Grey relational analysis}

The average measured data of machining performance including MRR, $R_{\mathrm{a}}$ and $G$ are shown in table 3 . The procedure of Grey relational analysis can be easily understood from figure 3. First, the 18 average data for MRR are set as the reference sequence denoted as $x_{0}(k)$. Those 18 values for $F_{\mathrm{r}}, T_{\text {on }}, T_{\text {off }}, V_{\mathrm{w}}, F_{\mathrm{w}}$ and $P$ were set

\begin{tabular}{rrrr}
\hline & & \multicolumn{2}{c}{$S / N$} \\
\cline { 2 - 4 } No. & MRR & $R_{\mathrm{a}}$ & $G$ \\
\hline 1 & 11.86 & -5.48 & 9.46 \\
2 & 11.72 & -5.63 & 10.08 \\
3 & 11.29 & -5.44 & 9.80 \\
4 & 14.12 & -7.91 & 7.46 \\
5 & 13.39 & -7.90 & 8.18 \\
6 & 14.23 & -7.48 & 7.26 \\
7 & 14.81 & -9.82 & 6.68 \\
8 & 14.52 & -9.94 & 6.94 \\
9 & 16.52 & -9.45 & 7.26 \\
10 & 13.32 & -4.83 & 10.27 \\
11 & 14.82 & -6.39 & 10.17 \\
12 & 13.99 & -5.11 & 10.17 \\
13 & 29.98 & -8.33 & 8.10 \\
14 & 29.92 & -8.33 & 7.56 \\
15 & 30.20 & -8.31 & 7.96 \\
16 & 30.70 & -9.08 & 7.13 \\
17 & 29.17 & -9.76 & 8.03 \\
18 & 29.68 & -9.901 & 7.6 \\
\hline
\end{tabular}

Table 4. $S / N$ value of machining performance. 


\begin{tabular}{lccccccc}
\hline $\begin{array}{l}\text { Machining } \\
\text { performance }\end{array}$ & Level & $F_{\mathrm{r}}$ & $T_{\text {on }}$ & $T_{\text {off }}$ & $V_{\mathrm{w}}$ & $F_{\mathrm{w}}$ & $P$ \\
\hline MRR & 1 & 122.48 & 77.00 & 114.80 & $116.68^{*}$ & $115.32^{*}$ & 113.76 \\
& 2 & $221.77^{*}$ & 131.83 & 113.53 & 113.57 & 115.25 & $115.27^{*}$ \\
& 3 & & $135.40^{*}$ & $115.90^{*}$ & 113.98 & 113.66 & 115.20 \\
$R_{\mathrm{a}}$ & 1 & $-69.06^{*}$ & $-32.87^{*}$ & -46.08 & -47.31 & -47.41 & -46.11 \\
& 2 & -70.67 & -48.28 & -47.95 & -46.69 & -46.60 & $-46.06^{*}$ \\
$G$ & 3 & & -58.58 & $-45.70^{*}$ & $-45.73^{*}$ & $-45.72^{*}$ & -47.57 \\
& 1 & 73.12 & $59.94^{*}$ & 49.10 & 50.35 & 48.71 & 49.96 \\
& 2 & $76.97^{*}$ & 46.50 & $50.93^{*}$ & $50.87^{*}$ & 49.74 & $50.21^{*}$ \\
& 3 & & 43.64 & 50.06 & 48.93 & $51.64 *$ & 49.92 \\
\hline
\end{tabular}

Table 5. $S / N$ value of all levels for MRR, $R_{\mathrm{a}}$ and $G$.

\begin{tabular}{lcccc}
\hline & \multicolumn{3}{c}{$V$} \\
\cline { 2 - 5 } Parameters & $f_{\mathrm{A}}$ & MRR & $R_{\mathrm{a}}$ & $G$ \\
\hline$F_{\mathrm{r}}$ & 1 & 547.78 & 0.145 & 0.8269 \\
$T_{\text {on }}$ & 2 & 178.5 & 27.9 & 12.627 \\
$T_{\text {off }}$ & 2 & 0.235 & 0.244 & 0.140 \\
$V_{\mathrm{w}}$ & 2 & 0.476 & 0.106 & 0.669 \\
$F_{\mathrm{w}}$ & 2 & 0.147 & 0.119 & 0.370 \\
$P$ & 2 & 0.122 & 0.122 & 0.004 \\
Error & 6 & 28.69 & 0.139 & 1.802 \\
\hline
\end{tabular}

Table 6. ANOVA analysis

\begin{tabular}{lcccc}
\hline Parameters & $F_{\mathrm{MRR}}$ & $F_{\mathrm{Ra}}$ & $F_{\mathrm{G}}$ & $F_{0.05, v 1, v 2}$ \\
\hline$F_{\mathrm{r}}$ & $19.096^{*}$ & 1.048 & 0.459 & 5.99 \\
$T_{\text {on }}$ & $6.222^{*}$ & $201.48^{*}$ & $7.007^{*}$ & 5.14 \\
$T_{\text {off }}$ & 0.008 & 1.758 & 0.078 & 5.14 \\
$V_{\mathrm{w}}$ & 0.017 & 0.766 & 0.371 & 5.14 \\
$F_{\mathrm{w}}$ & 0.005 & 0.858 & 0.205 & 5.14 \\
$P$ & 0.004 & 0.884 & 0.002 & 5.14 \\
\hline
\end{tabular}

Table 7. $F$-test value.

as six comparative sequences $x_{i}(k), i=1-6$ and $k=1-18$. To satisfy three characteristics of Grey relational analysis: normalization, scaling and polarization, the Grey generating process is necessary. From the results of $S / N$ ratio analysis in section 5.1.1, it was found that a larger $T_{\text {on }}, F_{\mathrm{r}}$ and $T_{\text {off }}$ are better for MRR. A smaller $V_{\mathrm{w}}$ and $F_{\mathrm{w}}$ are better for MRR. A medium $P$ is better for MRR. Therefore, the original data of sequences $F_{\mathrm{r}}(k), T_{\text {on }}(k)$ and $T_{\text {off }}(k)$ were calculated by equation (1) as HB. The Grey relational generating of sequences $V_{\mathrm{w}(k)}$ and $F_{\mathrm{w}}(k)$ should be calculated by equation (2) as LB and $P(k)$ is calculated by equation (3). Those Greygenerated data are shown in table 8 . In addition, the Grey relational grade of each machining parameter on MRR can be obtained by substituting those generating data into equation (6). In addition, the Grey relational grade of each machining parameter on $R_{\mathrm{a}}$ and $G$ can be found similarly as shown in table 9 . It is obvious that $F_{\mathrm{r}}$ 
Calculating $\mathrm{S} / \mathrm{N}$ value and finding the $\mathrm{HB}$ or LB characteristics of MRR、 $R_{a}$ and $G$
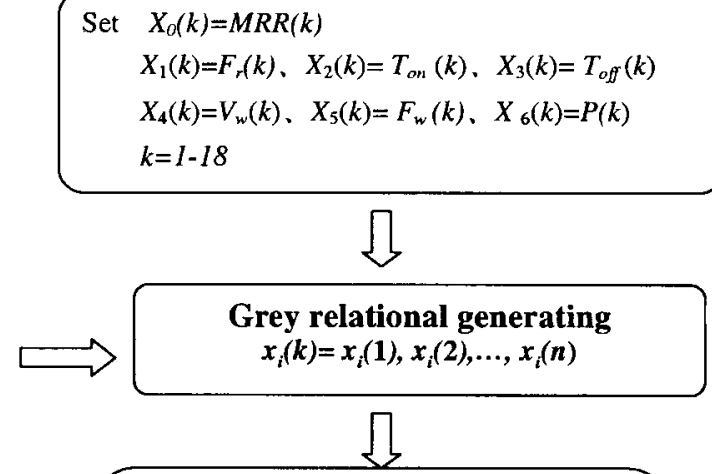

Calculating

$$
\begin{aligned}
& \Delta_{o i}(k)=\left|x_{0}(k)-x_{i}(k)\right| \\
& \Delta_{\operatorname{mim}}=\min _{\forall j \in i} \min _{\forall k}\left|x_{0}(k)-x_{j}(k)\right| \\
& \Delta_{\max }=\max _{\forall j \in i} \max _{\forall k}\left|x_{0}(k)-x_{j}(k)\right|
\end{aligned}
$$

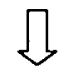

Calculating Grey relational grade

$$
\Gamma_{o i}=\frac{\Delta_{\min }+\Delta_{\max }}{\Delta+\Delta_{\max }}
$$

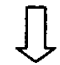

\section{Significant machining parameters}

$$
\left(F_{r} \text { and } T_{o n}\right)
$$

Figure 3. Flow chart of Grey relational analysis.

has significant influence on MRR. $G$ and $R_{\text {a }}$ are mainly influenced by $T_{\text {on }}$. The above results are the same as the discussion in Section 5.1 .1 by statistical analysis. Moreover, the significant machining parameter for whole machining performance (MRR, $R_{\mathrm{a}}, G$ ) is found as $T_{\text {on }}$ by taking the average of the Grey relational grade of MRR, $R_{\mathrm{a}}$ and $G$.

Hence, the influence of machining parameters on MRR, $R_{\mathrm{a}}$ and $G$ can be obtained by Grey relational analysis integrated with $S / N$ ratio calculation.

\subsection{Optimal machining parameters' setting}

Generally speaking, maximum MRR and minimum $R_{\mathrm{a}}$ should be considered simultaneously while manufacturing. To obtain the optimal machining parameters' combination for multiple quality requests, statistical analysis must integrate some other numerical methods like regression and the optimal mathematical theorem. However, it is quite direct and efficient to obtain the optimal machining parameters 


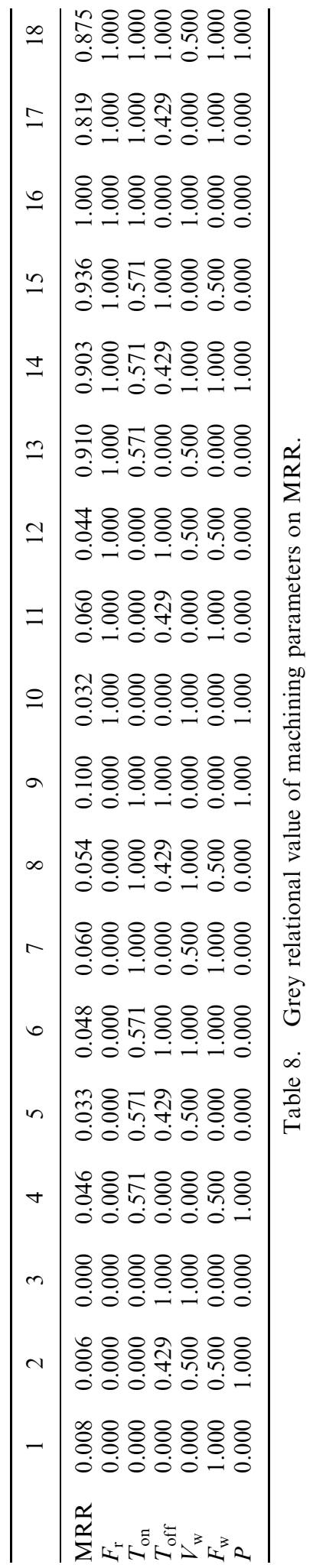




\begin{tabular}{lllll}
\hline Parameters & MRR & \multicolumn{1}{c}{$R_{\mathrm{a}}$} & $G$ & Total \\
\hline$F_{\mathrm{r}}$ & $0.7162^{*}$ & 0.6258 & 0.6419 & 0.6613 \\
$T_{\text {on }}$ & 0.6840 & $0.9186^{*}$ & $0.8595^{*}$ & $0.8207^{*}$ \\
$T_{\text {off }}$ & 0.6251 & 0.6472 & 0.6557 & 0.6426 \\
$V_{\mathrm{w}}$ & 0.6249 & 0.6532 & 0.6617 & 0.6466 \\
$F_{\mathrm{w}}$ & 0.6228 & 0.6548 & 0.6705 & 0.6493 \\
$P$ & 0.6149 & 0.6533 & 0.6496 & 0.6392 \\
\hline
\end{tabular}

Table 9. Grey relational grade for machining parameters on machining performance.

by Grey relational analysis among 18 experiments. First, a reference sequence $x_{0}(k)=\left\{x_{0}(1), x_{0}(2)\right\}=\left\{\mathrm{MRR}, R_{\mathrm{a}}\right\}=\{1,1\}$ is designed. The measured average data of MRR and $R_{\mathrm{a}}$ in table 3 are taken as 18 comparative sequences $x_{i}(k)=\left\{x_{i}(1), x_{i}(2)\right\}=\left\{\operatorname{MRR}(i), R_{\mathrm{a}}(i)\right\}, i=1, \ldots, 18$. In the Grey relational generating process, MRR is taken as HB and $R_{\mathrm{a}}$ is set as LB. The Grey relational grade $\left(\Gamma_{o i}\right)$ can be calculated by equation (6). It is clearly found from figure 4 that the machining parameters' setting of no. 15 has the highest Grey relational grade. Therefore, no. 15 is the optimal machining parameters' setting for maximum MRR and minimum $R_{\mathrm{a}}$ simultaneously among the 18 experiments.

Besides, for a desired $\mathrm{Ra}$ and maximum MRR, the optimal machining parameters can also obtained by Grey relational analysis. Taking a desired $R_{\mathrm{a}}=3 \mu \mathrm{m}$ (set as the reference sequence, $x_{0}(k)=\left\{\mathrm{MRR}_{(\max )}, R_{\mathrm{a}(3 \mu \mathrm{m})}\right\}=\{1,1\}$ as an example, the 18 values of MRR and $R_{\mathrm{a}}$ were substituted to equations (1) and (3) to obtain the Grey relational generating data. After the Grey relational generating and Grey relational grade calculation, the optimal machining parameters' setting can be obtained as no. 16 from figure 5. Hence, this approach is feasible to obtain effectively

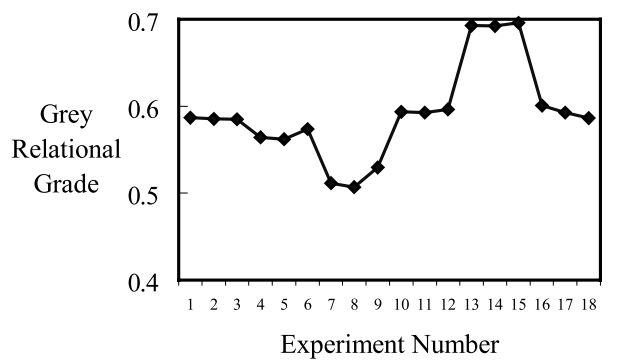

Figure 4. Grey relational grades for maximum MRR and minimum $R_{\mathrm{a}}$.

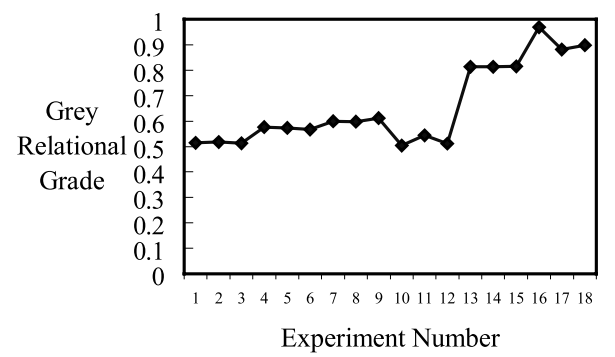

Figure 5. Grey relational grades for maximum MRR and a desired $R_{\mathrm{a}}(3 \mu \mathrm{m})$. 


\begin{tabular}{lcccccc}
\hline & $\begin{array}{c}F_{\mathrm{r}} \\
\left(\mathrm{mm} \mathrm{min}^{-1}\right)\end{array}$ & $\begin{array}{c}T_{\text {on }} \\
(\mu \mathrm{s})\end{array}$ & $\begin{array}{c}T_{\text {off }} \\
(\mu \mathrm{s})\end{array}$ & $\begin{array}{c}V_{\mathrm{w}} \\
\left(\mathrm{m} \mathrm{min}^{-1}\right)\end{array}$ & $\begin{array}{c}F_{\mathrm{w}} \\
(\mathrm{N})\end{array}$ & $\begin{array}{c}P \\
\left(\times 10^{5}\right) \mathrm{Pa}\end{array}$ \\
\hline $\begin{array}{l}\text { Manufacturer's manual } \\
\begin{array}{c}\text { This proposed approach } \\
\text { (no. 15 in table 1) }\end{array}\end{array}$ & 2.5 & 0.8 & 14.4 & 9 & 10 & 5 \\
\hline
\end{tabular}

Table 10. Machining parameters for maximum MRR and minimum $R_{\mathrm{a}}$.

optimal machining parameters for a desired $R_{\mathrm{a}}$ and maximum MRR by the Grey relational analysis.

\subsection{Evaluation of this proposed method}

For illustration purposes, two experiments were conducted under the conditions of maximum MRR and minimum $R_{\mathrm{a}}$. One set of machining parameters used the machining parameters provided by the manufacturer's machining manual. Another set adopted the no. 15 machining parameters given in table 1 . Those machining parameters were recorded in table 10. The experimental results are shown in table 11. It is clear that the proposed no. 15 machining parameters can obtain a higher Grey relational grade, which means it can obtain a better performance on MRR and $R_{\mathrm{a}}$ simultaneously.

Furthermore, comparison of this proposed approach with that of a well-skilled operator was conducted under the request of a desired surface roughness of $2.5 \mu \mathrm{m}$ and a desired gap width of $0.4 \mathrm{~mm}$ simultaneously. Those machining parameters adopted by a well-skilled operator in a factory and no. 5 in table 1 are shown in table 12. The experimental results are shown in table 13. It is obvious that the proposed optimal machining parameters can obtain a desired surface quality. In particular, a more accurate value of the desired dimension can be obtained.

\begin{tabular}{lccc}
\hline & MRR $\left(\mathrm{mm}^{3} \mathrm{~min}^{-1}\right)$ & $R_{\mathrm{a}}(\mu \mathrm{m})$ & Grey relational grade \\
\hline Manufacturer's manual & 34.50 & 2.94 & 0.6227 \\
$\begin{array}{c}\text { This proposed approach } \\
\text { (no. 15 in table 1) }\end{array}$ & 32.50 & 2.62 & 0.6953 \\
Improved percentage & & & 12 \\
\hline
\end{tabular}

Table 11. Machining performances for maximum MRR and minimum $R_{\mathrm{a}}$.

\begin{tabular}{lcccccc}
\hline & $\begin{array}{c}F_{\mathrm{r}} \\
\left(\mathrm{mm} \mathrm{min}^{-1}\right)\end{array}$ & $\begin{array}{c}T_{\mathrm{on}} \\
(\mu \mathrm{s})\end{array}$ & $\begin{array}{c}T_{\text {off }} \\
(\mu \mathrm{s})\end{array}$ & $\begin{array}{c}V_{\mathrm{w}} \\
\left(\mathrm{m} \mathrm{min}^{-1}\right)\end{array}$ & $\begin{array}{c}F_{\mathrm{w}} \\
(\mathrm{N})\end{array}$ & $\begin{array}{c}P \\
\left(\times 10^{5}\right) \mathrm{Pa}\end{array}$ \\
\hline $\begin{array}{c}\text { Well-skilled operator } \\
\begin{array}{c}\text { This proposed approach } \\
\text { (no. 5 in table 1) }\end{array}\end{array}$ & 2.3 & 0.5 & 12.8 & 7 & 10 & 7 \\
\hline
\end{tabular}

Table 12. Machining parameters for a desired gap width $0.4 \mathrm{~mm}$ and a desired $R_{\mathrm{a}}$ of $2.5 \mu \mathrm{m}$. 


\begin{tabular}{lccc}
\hline & $G(\mathrm{~mm})$ & $R_{\mathrm{a}}(\mu \mathrm{m})$ & Grey relational grade \\
\hline $\begin{array}{l}\text { Well-skilled operator } \\
\text { This proposed approach } \\
\text { (no. 5 in table 1) }\end{array}$ & 0.368 & 2.263 & 0.8566 \\
Improved percentage & 0.390 & 2.483 & 0.9568 \\
\hline
\end{tabular}

Table 13. Machining performances for a desired gap width $0.4 \mathrm{~mm}$ and a desired $R_{\mathrm{a}}$ of $2.5 \mu \mathrm{m}$.

\section{Conclusions}

Based on the Taguchi L18 mixed orthogonal table, only 18 experiments need to be conducted to find the significant machining parameters. According to the integration of Grey relational analysis and $S / N$ ratio, it is concluded that table feedrate and $T_{\text {on }}$ have the main influence in MRR, and $T_{\text {on }}$ has a significant influence on $G$ and $R_{\mathrm{a}}$. Moreover, the significant machining parameter for whole machining performance was $T_{\text {on }}$.

By Grey relational analysis, the optimal machining parameters' setting can be obtained for the simultaneous consideration of the maximum MRR and minimum $R_{\mathrm{a}}$. Furthermore, this approach is feasible to obtain the optimal machining parameters for a desired $R_{\mathrm{a}}$ and a desired $G$ (or maximum MRR) simultaneously by Grey relational analysis. In conclusion, this approach can be applied extensively to other cases in which performance is determined by many parameters at multiple quality requests.

\section{References}

Deng, J. L., 1989, Introduction to grey system. Journal of Grey System, 1, 1-24.

Deng, J. L., 1990, A Course on Grey System Theory (Wuhan, PRC: HUST).

HAM, I. and LU, S. C. Y., 1988, Computer-aided process planning: the present and the future. Annals of the CIRP, 37, 591-601.

Hsia, K. H. and WU, J. H., 1998, A study on the data preprocessing in Grey relation analysis. Journal of the Chinese Grey System Association, 1, 47-53.

Kishi, M., SuzuKi, S. and Araya, S., 1989, Optimization of multi-stage planetary machining parameters in NC die sinking EDM. Proceedings of the 9th International Symposium for Electro-machining (ISEM 9), Nagoya, Japan, pp. 34-37.

Kravets, A. T., 1992, Planning of the Wire-EDM process. Proceedings of the 10th International Symposium for Electro-machining (ISEM-10), Germany, pp. 218-222.

Liao, Y. S., Huang, J. T. and Su, H. C., 1997, A study on the machining parameters optimization of the wire electrical discharge machining. Journal of Materials Processing Technology, 71, 487-493.

LIN, J. L. and TARNG, Y. S., 1998, Optimization of the multi-response process by the Taguchi method with Grey relational analysis. Journal of Grey System, 4, 355-370.

Ross, P. J., 1986, Taguchi Techniques for Quality Engineering (New York: McGraw-Hill).

Scott, D., Boyina, S. and Rajurkar, K. P., 1991, Analysis and optimization of parameter combination in wire electrical discharge machining. International Journal of Production Research, 29, 2189-2207.

Staelens, F. and Kruth, J. P., 1989, Computer integrate in EDM planetary. Annals of the CIRP, 38, 187-190.

Tarng, Y. S., Ma, S. C. and Chung, L. K., 1995, Determination of optimal cutting parameters in wire electrical discharge machining. International Journal of Machine Tools and Manufacture, 35, 1693-1701. 